\title{
Study of Classroom Teaching Mode Innovation based on Mobile Internet
}

\author{
Yibo $\mathrm{Hu}^{1, \mathrm{a}}$ \\ ${ }^{1}$ Xi'an International University, Xi'an, Shaanxi, 710077 \\ a email
}

Keywords: Mobile Internet, Teaching Model, Innovation

\begin{abstract}
Under the impact of the information technology revolution, the mobile Internet to "moisten things silently" gesture quietly changing the traditional education model, and even subvert the traditional classroom teaching, prompting people to think to find a new classroom teaching. So it appeared buzzwords "Mu class" "micro-lesson" "flipped classroom" and Teaching Reform. This form of teaching from the United States, has attracted many domestic schools and educational administrative departments of the attention, in the classroom full use of the mobile Internet will not only help to improve the infrastructure of classroom teaching, but also to break the traditional to a certain extent teaching concept, content and methods to enhance the effectiveness of teaching and level [1]. No doubt the development of mobile Internet technology to the current classroom teaching reform has brought new opportunities, then how to seize the opportunity of the mobile Internet and the combination of classroom teaching and the use of it? This paper describes several Internet-based classroom teaching, analyzes it and gives the principles applicable to implement the recommendations.
\end{abstract}

\section{Introduction}

In recent years, the price of smart phones, tablet computers and other equipment for declining coverage portable, real-time, the introduction of efficient mobile Internet and 3G, wifi, 4G and other large-scale network signal is to let the growing popularity of the mobile terminal, which is the school teaching It provides a new mode of implementing the concept of classroom support. These patterns can make up some places of outstanding teachers short board scarce resources, so that teaching is no longer bound by space of time. Let's look teachers teaching content, enrich teaching methods to improve students' classroom lectures efficiency. Therefore appropriate to carry out research and innovation model is necessary.

Mu class. The term "Mu lesson" from the first to the West. That Massive Open Online Course, Acronym MOOC,

It refers to a massive open online courses, originally mainly some Western universities to excellent course free to publish the sharing of resources on the Internet, but education enthusiast, or experts in the field to provide the "volunteer" services, pole earth to enhance the efficiency of knowledge transfer [2]. Later it grew into individual and organizational knowledge Upload mutual learning. "Mu class" model actual classroom to emphasize that with the "micro-video" (micro class), each video is generally not more than one quarter of an hour, to facilitate students to concentrate and solve problems step by step, so that the effect of considerable learning .

Flipped classroom. "Flipped classroom" (English called Inverted Classroom) is a student in the teacher's "teaching and learning with the" reverse for teachers in "appropriate learning and teaching" the new teaching model students. By re-adjust over time out of the classroom, the decision to transfer learning from the teacher to the students, the teacher is no longer focused specifically occupy students' time is no longer taught in the complete reunification of the time, is no longer a whole classroom planners, the body becomes a student from the students in active learning self-learning state, just as the organizers and teachers maintain discipline people. This teaching model by watching video lectures (usually a teacher prerecorded tidied), listen to lectures recording, or read on the mobile client software, even to free access to information on the Internet, and then brainstorm to solve learning problems. Finally, there do not understand the teachers coaching. In this way, students learn more targeted, but also truly individualized teaching philosophy. 
Synchronous classroom and deliver classroom. "Synchronous classroom" English is the Synchronous Classroom, which is to reach the school and the school, classroom buildings and even coordinated students and parents, the use and convenience and advantages of mobile terminals Internet, to achieve synchronous learning, synchronous detection, simultaneous evaluation, such as in classroom outside the classroom and on the establishment of networking, build communication platform, even if not in school can get their lessons [3]. "Passing the classroom" (Transfer Classroom) refers to the additional resources and by sharing between the realization of knowledge transfer. Excellent open class as a school teacher can be transmitted to other school teachers group or forum for community learn from.

Second, the advantages and disadvantages of the new model in the classroom under the Mobile Internet

\section{The Advantages of the New Model in the Classroom under the Mobile Internet}

To carry out new classroom model to break the traditional "one size fits all, chalk and talk," the rigid class model. This model is conducive to play the leading role of teachers, but also fully embodies the student's sense of ownership. To mobilize the enthusiasm of both interest and the class has a very significant role. The use of smart phones, tablet, online video and other new equipment, triggering the curiosity of students, expanding the mind, and flexible attendance mode to meet the different needs of students.

Students pay more attention to the emotional attitudes and values. Traditional teaching philosophy where there are usually three levels of objectives, and the general focus on the target culture knowledge and ability, often ignoring the emotional goals. New mobile Internet classroom teaching model not only attaches importance to developing students' knowledge and skills, but also take care of the process and methods of learning, emotional attitude and values, into a more humane care philosophy, consistent with the purpose of quality education. At the same time, from the student perspective, a conventional classroom lethargic, unwilling to raise their hands to speak dilemma has also been improved, more and more students willing to ask questions and feedback to teachers teaching platform.

Traditional classroom teaching too much emphasis on the acceptance of learning, and the network of classroom teaching only emphasizes inquiry-based learning. New network classroom teaching process and methods emphasize student learning is the key to guide students to learn to learn. New Open Teaching Mode experience, explore and cooperation led to the students' practical, pragmatic and hands-on in practice to test access to knowledge. Undoubtedly exercise their thinking. In addition, in the form of teamwork, student exchanges and communication level has been greatly improved [4].

\section{The Lack of New Models in the Classroom under Mobile Internet}

Undeniably flipped classroom peer network on innovative teaching mode of teaching in large part to provide a convenient for students to learn more effectively, make the classroom more harmonious, but for now the actual situation of the promotion, there really is inadequate and needs improvement.

First of all, we can not $100 \%$ guarantee that students did not meet the autonomy envisaged. Especially schoolchildren. Their mental development is not mature enough, the lack of awareness and planning, class, if there is no good control, it is easy to get out of control, the opposite effect. For example, in using the flipped classroom model, because they do not focus on the wrong way or another, can not lead to full use of electronic materials teachers organize learning. Another example is the video released after the teaching, the students' classroom teachers viewership is not good grasp.

New Mode for Teacher Education has brought opportunities as well as challenges. Aspects of IT operations to the level of the teachers put forward higher requirements. Video recordings and other materials and the search process is very complex, potentially increasing the pressure on teachers. On the one hand to ensure the quality of the material, on the other hand to consider the effect of 
recording, as well as unexpected situations encountered during recording, sometimes it may only be a person with no way to force the completion of complex courseware recording work, take a few and even some individual cooperative production, video editing projects or post, upload tasks require expertise to help.

Waste of resources to some extent. If the front of the mobile client side download each student, learning, watching the teacher in the classroom for students to make the "Video", you have to let us think: Since teachers and students in the classroom, and that the traditional sense of the teacher What is the difference between the way the scene lectures, classroom teaching to lose the most valuable resource of the original communication and discussion. "Teaching in the final analysis, human activity, if too flip, flip blindly, eventually lost teaching model innovation in mind.

Emphasis on student burden in the implementation of mobile Internet innovation classroom model, because of micro-video, electronic courseware for multiple uses, either before class or classes, have increased the burden of student learning. And after school, then more obvious, although teachers do not lecture, but the students to see the teacher's "micro-video" or equal to listen to the teacher in class, but it is for the occasion and outerwear. In fact many school students polarization phenomenon is very serious, the teacher in the classroom to the hierarchical teaching, promote individualized, which is "Mu class" and "micro-lesson" that made uniform, the bulk of the teaching mode is difficult to achieve of. After all, no man-made as flexible.

Strengthen mode selection consciousness. Awareness of the impact of action. What kind of appropriate educational concepts, there will be what kind of educational activities. Targeting teachers has been since ancient times: preaching Tuition FAQ. This understanding is not wrong, but the only way of understanding is not enough. Teachers should be aware of their roles change, truly student-centered, clearly aware of their duty to guide, with a more appropriate model to organize classroom teaching. In the Internet environment should pay more attention. First, the need for the production of micro-video. Good video can play a finishing touch. To dapper exciting content, focused, and thinking and ornamental value, so that it can make the classroom efficiency play bigger limits. Second, we must consider whether the content of the show ability to accept students. Students learn easier, have the initiative to accept new knowledge possible. Third, we must define the scope of application of various teaching models. Should be treated differently for preview video and the classroom teacher lectures video, video and video in school at home, truly expedient.

Improving Teachers Information Technology. When life in the information age, students may for a wide variety of eye full of electronic products and various types of software has a natural sense of intimacy and familiarity [4]. However, due to the different growth environment, the contact is not the same thing, is that most of the teachers to use computers on the Internet, write documents, making PPT courseware, software and other technologies have little chance to get in contact. Teachers do not have the range of skills associated with the preparation of instructional videos, then, to promote the "flipped classroom" reform is difficult. Therefore, teachers in addition to enhance their professional qualities, the mobile Internet is the use of high-tech training should focus on aspects arrested.

Equipped hardware facilities. To avoid too many students occupy their spare time, and to give students a real burden, while allowing a new model of mobile Internet to get a wider range of universal access, on the one hand to try to meet the mobile Internet in the classroom, "Accessibility". And taking into account the interactive teaching process using the mobile network the phone will have a greater network traffic, it will produce a relatively large cost, in order to save costs class students and teachers can take a free real-name system login account Campus Educational way to access the campus radio Internet, on the other hand to ensure that the smart phone, tablet PC configuration.

\section{Conclusion}

Based on the teaching mode mobile Internet era of fully integrated university students' interest, through the smart phone to achieve effective classroom learning. Rational use of the teaching model not only to maximize the student body in the learning process and creativity to improve the 
awareness of active learning, these are our every teacher should do.

\section{Acknowledgements}

The paper phased research results: in 2015, the ministry of education of education management information center subject "MOOCs vision under the information technology and subject teaching depth fusion research on corpus" teaching model of college students based on MOOCs post competency force research, project number: ElJYB2015053; 2015 scientific research projects in shaanxi province department of education under the background of the transformation of run by the local undergraduate college talent training quality evaluation standard research, project number: 15 jk2134; Xi 'an institute of foreign affairs in 2015 field the educational reform subject "based on the study of the teaching mode of college students post competency force MOOCs, project number: 2015 b03; 2015 in shaanxi province education department of higher education teaching reform project "of higher continuing education of the construction of the" three type "teachers research, project number: 37.

\section{References}

[1] Han Xiufeng, Xin Ping. Research teaching mode "flipped classroom" Situation [J]. Exam Week. 2016 (15).

[2] Chen Yiming. Age Teaching Environment and Teaching Mode Internet [J]. Southwest China Normal University .2016 (03).

[3] Wu Qindong. Based on the concept of the flipped classroom teaching model [J]. Science Week .2016 (15).

[4] Ma Yunyan. Teaching method of the mobile Internet. Modern women (late) [J]. 2014 (10).

[5] Guo Meiying. Explore the mobile Internet-based dissemination of experience teaching model [J]. Yunnan Open University. 2015 (03). 